\title{
Spatially Modulated Laser Beam Micro Welding of CuSn6 and Nickel-plated DC04 Steel for Battery Applications
}

\author{
Benjamin MEHLMANN ${ }^{* 1}$, Alexander OLOWINSKY ${ }^{* 1}$, Michael THUILOT ${ }^{* 1}$ and Arnold GILLNER ${ }^{* 1}$ \\ ${ }^{* 1}$ Fraunhofer Institute for Laser Technology ILT, Steinbachstr. 15, 52074 Aachen, Germany \\ E-mail: benjamin.mehlmann@ilt.fraunhofer.de
}

\begin{abstract}
Lithium-ion battery cells are being increasingly used as energy storage devices for electrically powered vehicles on account of their high energy density. 18650-type cells provide an ideal solution thanks to their low price and ready availability. Compared with large-format cells, however, these cells have low capacity, which is why several individual cells have to be connected in parallel to create larger cells or suitable battery packs. In these cases, overlap welding is commonly used to join a copper current collector and battery can - the negative pole - made out of nickel-plated DC04 steel. The major challenge in welding batteries is melting both parts without damaging the can and causing the electrolyte to leak. Spatial modulation can be used to control weld depth very precisely. In this paper, we present recent developments in spatial modulation of laser radiation for welding the material combination of copper and steel in the field of battery welding and discuss the influence of the modulation amplitude. Also, we show the extent to which tensile strength influences the joint and the electrical resistance.
\end{abstract}

DOI: $10.2961 /$ jlmn.2014.03.0019

Keywords: Laser micro welding, 18650, battery, copper, steel, bronze, power modulation

\section{Introduction}

Lithium-ion battery cells are being increasingly used as energy storage devices for electrically powered vehicles on account of their high energy density. 18650-type cells which are mainly used in notebooks and power tools - provide an ideal solution thanks to their low price and ready availability. Compared to large-format cells, however, these cells have low capacity, which is why several individual cells must be connected in parallel to create larger cells or suitable battery packs. In these cases, overlap welding is used to join a copper current collector and battery can - the negative pole - made out of nickel-plated DC04 steel. The welding is done after cell production so the cell is charged and filled with the cathode and anode material, the separator and the liquid electrolyte.
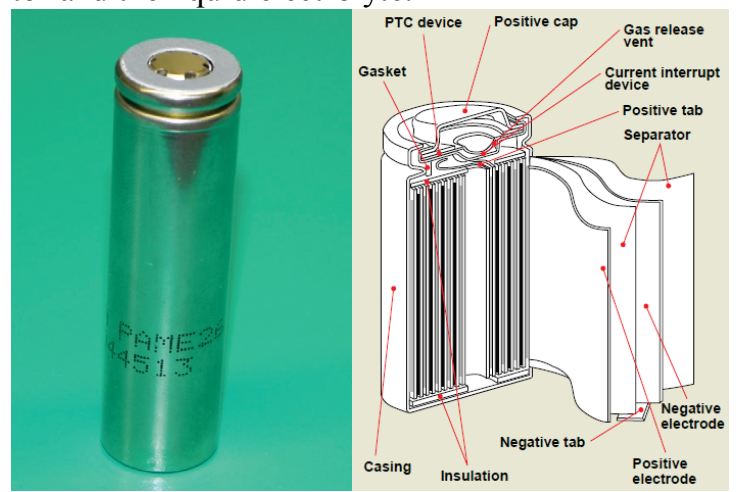

Fig. 1 (a) 18650 battery cell (b) schematic view of cell makeup (source: Sanyo)

The major challenge in welding of batteries is melting both parts - in our case CuSn6 sheet on top and the battery can on the bottom - without damaging the can and causing the electrolyte to leak.
Spatial power modulation - a linear feed with a superposed circular modulation - can be used to control weld depth very precisely. It also reduces the possibility of the weld penetrating through the material, which would damage the can. The requirements for this approach are high beam quality as well as high dynamics in beam movement $[1,2]$.

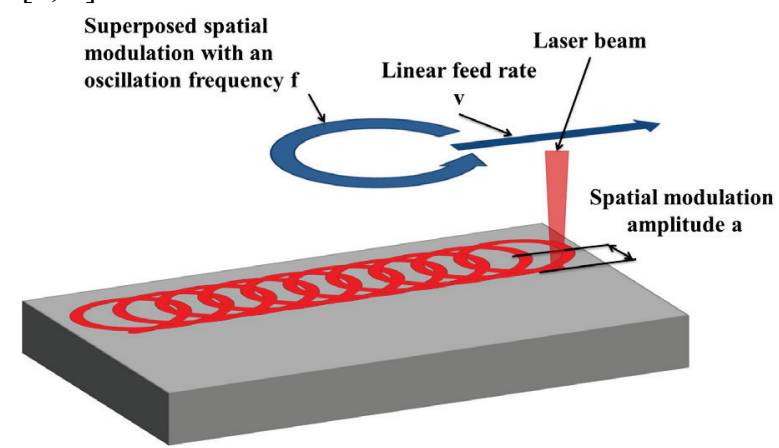

Fig. 2 Schematic view of spatial modulation, incl. necessary parameters

The usage of high brightness laser sources for welding of copper alloys has been introduced by e. g. [3]. Although the quality for this application is low, a variation in weld depth has been observed for bronze CuSn6 [3]. Disadvantageously, the connection area of an overlap joint welded by a high brightness laser beam is small, which renders it less suitable. To increase the seam width and, thus, the strength of the connection, an increase of line energy is necessary, simultaneously heightening the risk of welding through the can. So in this paper, we have investigated the usage of spatial modulation and its effect on joint quality. In addition, the influence of thermal cycling on the joint for the specified usage temperatures of the battery cell has been studied. 
Problems can arise from the combination of these two materials, resulting either from a difference in CTE (CuSn6: $18,0 \cdot 10^{-6} \mathrm{~K}^{-1}[4]$, Fe: $11,7 \cdot 10^{-6} \mathrm{~K}^{-1}[5]$ ), which can cause stress resulting in cracks [6], or from the difference in liquidus temperatures.

\section{Experimental Setup}

As mentioned, the welding configuration is an overlap joint. The CuSn6 sheet has a thickness of $200 \mu \mathrm{m}$, the battery can has a wall thickness of $250 \mu \mathrm{m}$ and consists of nickel-plated DC04-steel. The CuSn6 sheet is welded to the bottom of the can (s. Fig. 3). The welding contour is a line of $5 \mathrm{~mm}$.

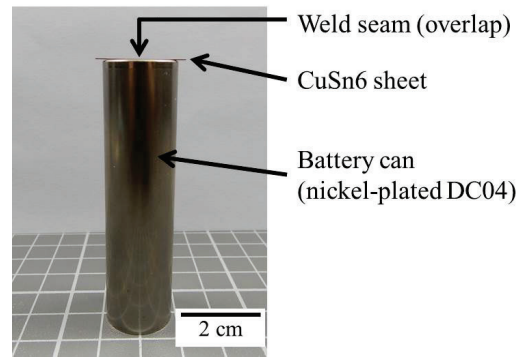

Fig. 3 Battery can and sheet material in overlap configuration

A fiber laser (SPI SP 200C) was used with a central wavelength of $1075 \mu \mathrm{m}$ and a continuously variable power output up to $200 \mathrm{~W}$ with a beam quality of $\mathrm{M}^{2}<1.1$. The beam was deflected by a galvanometric scanner (Scanlab SK1020) and focused by a telecentric f-theta lens with a focal length of $80 \mathrm{~mm}$. The spatial modulation was also performed by the galvanometric scanner.

The cylindrical battery cells were each halved lengthwise in order to simplify handling and they are clamped with a CuSn6 sheet for welding. No shielding gas was used.

For the investigation the output power $\mathrm{P}$ of the laser source, the feed rate $\mathrm{V}$ and the amplitude of the spatial modulation a were varied. The oscillation frequency $f$ of the spatial modulation was kept at $1 \mathrm{kHz}$.

To evaluate the mechanical strength of the welded samples, the maximum force was determined by tensile testing. Due to their special geometry, the samples were clamped between a mandrel and the jaws of the testing machine (Fig. 4). The clamping jaws were arranged perpendicular to each other.

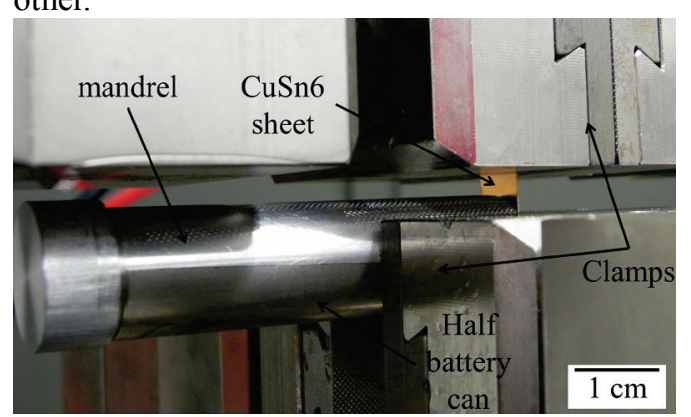

Fig. 4 Tensile testing set up

The samples were subjected to a constantly increasing force; the test speed was $50 \mathrm{~mm} / \mathrm{min}$. The samples were pulled along the weld. For each set of parameters, three samples were tested. The error indicated in the graphs was calculated by using population standard deviation.

In addition to fixing the joint mechanically, the weld constitutes the electrical contact of the battery cell; there- fore, the size of the electric resistance is of interest. In order to have an efficient battery pack, the resistance at each joint must be minimized. A four-wire measurement was used to determine the resistance of the joint. The contact resistance is composed of the respective individual resistances of copper and steel sheet and the actual contact resistance of the connection. Due to the special geometry of the sample, the measurement was performed on the inside of the battery can. The arrangement of the measuring head on the sample is shown in Fig. 5.

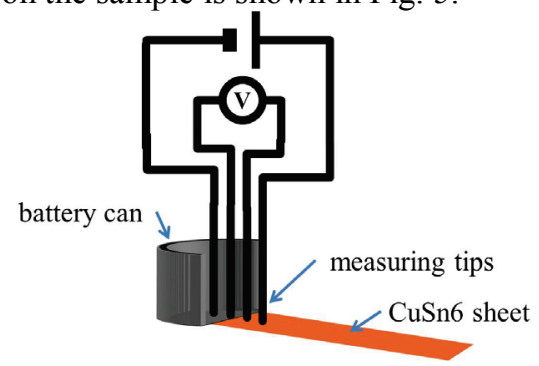

Fig. 5 Test setup for measuring the resistance

To view the effects of thermal cycling on the joint, the welded samples were subjected to heating and cooling. Due to the different CTE of the joined material, mechanical stress can lead to cracking, and this may reduce the strength of the joint or increase the resistance. To detect the influence of frequent temperature changes, the climate chamber Weiss WK-270/70/10 was used. The samples were subjected to a certain number of thermal cycles, and then the resistance and the maximum breaking force were determined. For the thermal cycling only samples with a feed rate of $100 \mathrm{~mm} / \mathrm{s}$ were investigated and compared to samples that did not undergo the thermal cycles. The test parameters according to DIN EN 60068-2-14 are the ambient temperature, the upper and lower temperatures of a cycle, the dwell time at the upper and lower temperatures, the changing rate of the temperature and the number of test cycles. The ambient temperature in the laboratory was a constant $21^{\circ} \mathrm{C}$.

With respect to the use of the battery cell in a car, the temperatures that occur in extreme cases were considered and set to the minimal and maximal temperature of typical 18650 cells. The lower temperature limit is $-10^{\circ} \mathrm{C}$ and as the upper limit the temperature of $60^{\circ} \mathrm{C}$ was set. Since the samples have a low mass and rapidly assume the temperature of the test chamber, a dwell time at the temperature limits of $10 \mathrm{~min}$ was sufficient. According to a recommendation of DIN EN 60068-2-14, the changing rate of temperatures was set to $3 \mathrm{~K} / \mathrm{min}$. This resulted in a cycle time of $73.33 \mathrm{~min}$; the samples were subjected to a total of 60 cycles.

\section{Results and Discussion}

In order to determine the process window, the laser output power $\mathrm{P}$ was set to $130 \mathrm{~W}$ and increased for each weld by steps of $5 \mathrm{~W}$ until the full penetration of both materials occurred. For this no spatial modulation was used and the feed rate $\mathrm{v}$ was set to $100 \mathrm{~mm} / \mathrm{s}$. The first full penetration of the weld seam was visible at $175 \mathrm{~W}$; therefore, the upper limit of the power output for the testing was set to $170 \mathrm{~W}$. Based on this, two other, lower levels of laser output power were defined, which are $160 \mathrm{~W}$ and $150 \mathrm{~W}$. These three power levels and the feed rate together form 
certain energy input per unit length, which was kept constant for feed rate variation.

The parameter realm for the amplitude of spatial modulation is defined with the lower limit being welding without modulation and the upper limit being the amplitude for which the welding with the lowest energy input per unit length leads to a joint. When the amplitude was increased gradually in steps of $0.05 \mathrm{~mm}$ at a feed rate of $90 \mathrm{~mm} / \mathrm{s}$, the first time the joining does not occur is at an amplitude of $0.2 \mathrm{~mm}$. Therefore, an amplitude of $0.15 \mathrm{~mm}$ was defined as the upper limit. The specified test parameters are shown in Table 1.

Table 1 Testing parameters

\begin{tabular}{ll}
\hline Test parameters & Parameter levels \\
\hline Feed rate & $90 ; 100 ; 110[\mathrm{~mm} / \mathrm{s}]$ \\
Energy input per unit length & $1.5 ; 1.6 ; 1.7[\mathrm{~J} / \mathrm{mm}]$ \\
Laser output power for $\mathrm{v}=90 \mathrm{~mm} / \mathrm{s}$ & $135 ; 144 ; 153[\mathrm{~W}]$ \\
Laser output power for $\mathrm{v}=100 \mathrm{~mm} / \mathrm{s}$ & $150 ; 160 ; 170[\mathrm{~W}]$ \\
Laser output power for $\mathrm{v}=110 \mathrm{~mm} / \mathrm{s}$ & $165 ; 176 ; 187[\mathrm{~W}]$ \\
Amplitude of spatial modulation & $0 ; 0.05 ; 0.1 ; 0.15$ \\
& {$[\mathrm{~mm}]$} \\
\hline
\end{tabular}

The spatially modulated welds display a scaled surface. This scaled structure is the main visible difference to weld seams produced without spatial modulation. The welds produced without spatial modulation are smoother and narrower than the other seams. There is no difference in the appearance of the weld seam over different laser powers, whereas differences are visible for different feed rates. For the upper feed rate, the surface of the weld seam is distorted due to the constant modulation frequency of $1 \mathrm{kHz}$.

In cross sections, the difference between the modulated and unmodulated welds is visible. The unmodulated weld has a larger aspect ratio and creates a fully penetrated weld seam. The spatially modulated welds have a greater con-

$$
\begin{gathered}
\mathrm{P}=170 \mathrm{~W} ; \mathrm{v}=100 \mathrm{~mm} / \mathrm{s} ; \quad \mathrm{P}=170 \mathrm{~W} ; \mathrm{v}=100 \mathrm{~mm} / \mathrm{s} ; \\
\mathrm{a}=0 \mathrm{~mm} ; \mathrm{f}=0 \mathrm{kHz}
\end{gathered}
$$

nection area, especially the welds with an amplitude of $0.15 \mathrm{~mm}$ (fig. 6).

The cross section (Fig. 6) shows that the parameter combinations of $\mathrm{v}=100 \mathrm{~mm} / \mathrm{s}$, and $\mathrm{P}=170 \mathrm{~W}, \mathrm{P}=150 \mathrm{~W}$ without spatial modulation already exhibit a full penetration. Therefore, these combinations cannot be used to weld of batteries contrary to the initial assessment.

Process instabilities occur predominantly, but not exclusively, at the welds without spatial modulation. They manifest themselves, for example, by a transition to the conduction welding or holes in the weld.

The maximum tensile force needed to destroy a sample can be used as a direct indicator for the strength of the connection. The greater the force is, the greater both the connecting area and, thus, the strength of the connection are.

Figure 7 displays the curve of the maximum tensile force as the modulation amplitude is varied at a feed rate of $100 \mathrm{~mm} / \mathrm{s}$ for different laser output powers. Higher laser output powers lead to increased strengths of the connections. The increase in laser output power directly increases the connection's cross-section. This effect is stronger for spatially modulated welds than for welds without modulation. The increase in the laser output power from the lowest to the highest for the unmodulated welds leads to an increase in the tensile force of about $20 \mathrm{~N}$. When spatial modulation is used with an amplitude of $0.1 \mathrm{~mm}$, tensile force is increased by about $150 \mathrm{~N}$ from lower power level to upper power level. For the lowest power level, a drop of about $60 \mathrm{~N}$ occurs in the measured maximum tensile force between the amplitudes of $0.1 \mathrm{~mm}$ and $0.15 \mathrm{~mm}$.

A direct correlation between the amplitude of the spatial modulation and the strength of the connection can be derived from the measurements. An increase in amplitude up to $0.1 \mathrm{~mm}$ leads to a larger tensile strength. A further increase to an amplitude of $0.15 \mathrm{~mm}$ does not result in higher strength. Notably, for the lowest power level the strength drops. This is caused by an insufficient weld depth.

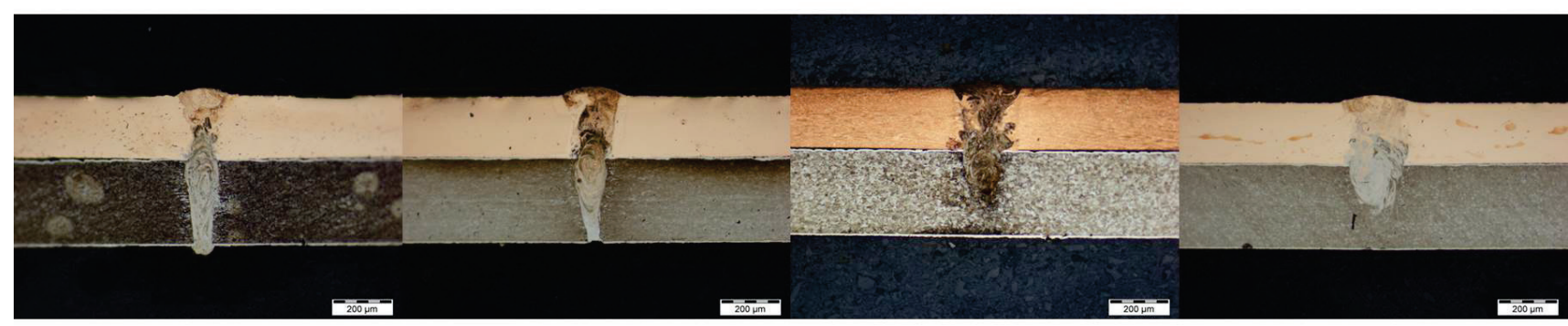
$\mathrm{P}=150 \mathrm{~W} ; \mathrm{v}=100 \mathrm{~mm} / \mathrm{s}$;
$\mathrm{P}=150 \mathrm{~W} ; \mathrm{v}=100 \mathrm{~mm} / \mathrm{s}$
$\mathrm{P}=150 \mathrm{~W} ; \mathrm{v}=100 \mathrm{~mm} / \mathrm{s}$;
$\mathrm{P}=150 \mathrm{~W} ; \mathrm{v}=100 \mathrm{~mm} / \mathrm{s}$; $\mathrm{a}=0.1 \mathrm{~mm} ; \mathrm{f}=1 \mathrm{kHz}$ $\mathrm{a}=0.15 \mathrm{~mm} ; \mathrm{f}=1 \mathrm{kHz}$

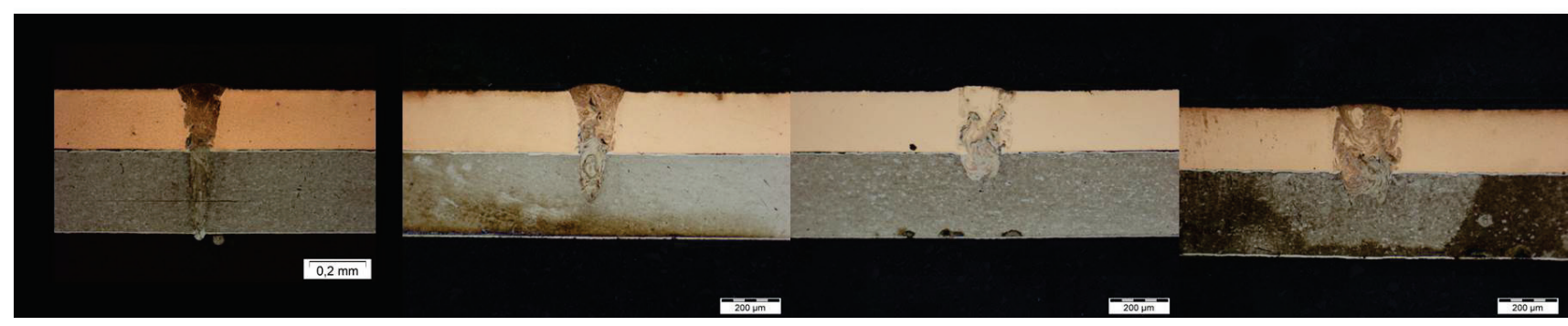

Fig. 6 Cross sections of different welds with CuSn6 on top and DC04 steel on the bottom 


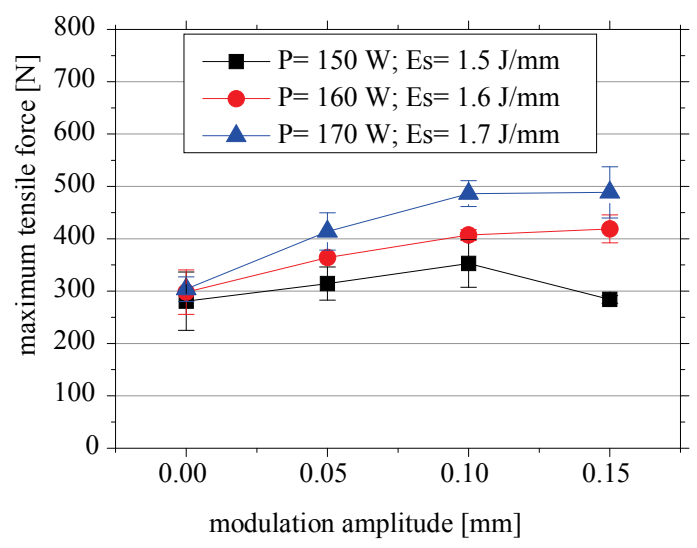

Fig. 7 The measured maximum tensile force of welds produced with $\mathrm{v}=100 \mathrm{~mm} / \mathrm{s}$

Similar relationships apply for the test series at a feed rate of $110 \mathrm{~mm} / \mathrm{s}$ (Figure 8 ).

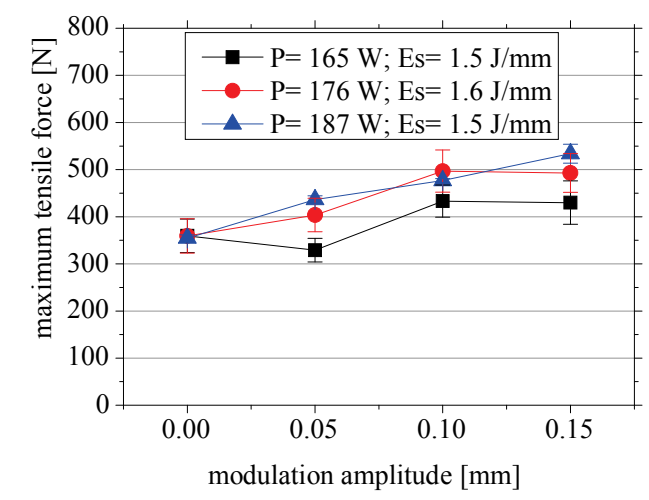

Fig. 8 The measured maximum tensile force of welds produced with $\mathrm{v}=110 \mathrm{~mm} / \mathrm{s}$

At $\mathrm{v}=110 \mathrm{~mm} / \mathrm{s}$, the strength of the joint is less influenced by laser power. The difference in tensile strength increases from the lowest to the highest power level for all welds with spatial power modulation and reaches a maximum of $100 \mathrm{~N}$. As in the experiments with $\mathrm{v}=100 \mathrm{~mm} / \mathrm{s}$, results show a greater tensile strength for larger amplitudes. But no drop of the strength is observed for Es $=1.5 \mathrm{~J} / \mathrm{mm}$ at an amplitude of $0.15 \mathrm{~mm}$.

The measured maximum tensile forces of the lowest feed rate of $90 \mathrm{~mm} / \mathrm{s}$ are shown in Figure 9. The laser output power has the greatest influence on the measured maximum force for this setting when compared to the other feed rates. Depending on the energy input per unit length, tensile strength drops between amplitudes of $0.05 \mathrm{~mm}$ and $0.1 \mathrm{~mm}(\mathrm{Es}=1.5 \mathrm{~J} / \mathrm{mm}$ and $\mathrm{Es}=1.6 \mathrm{~J} / \mathrm{mm})$. For $\mathrm{Es}=$ $1.7 \mathrm{~J} / \mathrm{mm}$ the drop occurs between amplitudes of $0.1 \mathrm{~mm}$ and $0.15 \mathrm{~mm}$. This is similar to welds with $\mathrm{P}=150 \mathrm{~W}$ and $\mathrm{v}=100 \mathrm{~mm} / \mathrm{s}$. The force for the parameter of laser output power of $135 \mathrm{~W}$ and amplitude of $0.15 \mathrm{~mm}$ is specified as $0 \mathrm{~N}$ because the samples were destroyed in the preload phase of tensile testing; the maximum reachable tensile force is seen as negligible.

The increase of the modulation amplitude up to $0.05 \mathrm{~mm}$ leads to an increase in maximum tensile force compared to unmodulated welds. For samples welded with a laser output power of $135 \mathrm{~W}$ and $144 \mathrm{~W}$, the measured force already decreases at an amplitude of $0.1 \mathrm{~mm}$.

Therefore, the measured maximum tensile force is not constant when compared to the same energy input per unit length at the same amplitudes, but it is dependent upon absolute laser output power. This is also indicated by the comparison between the maximum measured forces at a feed rate of $90 \mathrm{~mm} / \mathrm{s}$ and the laser output power of $153 \mathrm{~W}$ and a feed rate of $100 \mathrm{~mm} / \mathrm{s}$ and $150 \mathrm{~W}$. The difference in the energy input per unit length only causes a higher measured force, but this does not alter the course of maximum measured force over the amplitude.

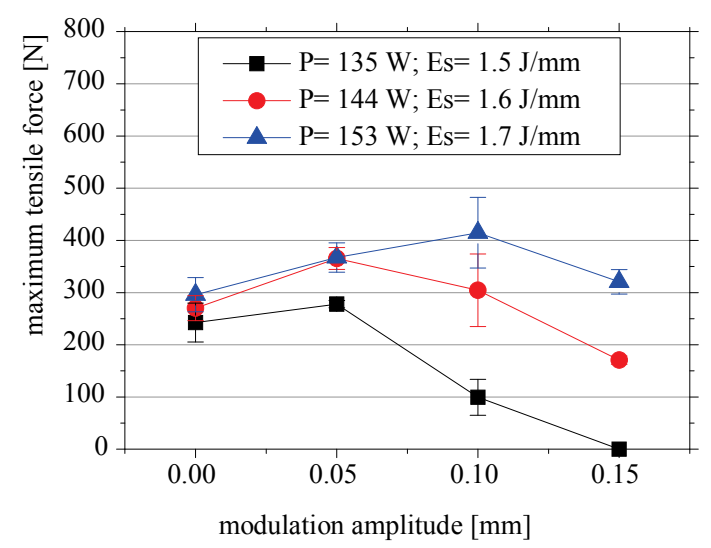

Fig. 9 The measured maximum tensile force of welds produced with $\mathrm{v}=90 \mathrm{~mm} / \mathrm{s}$

The optimum strength was obtained as a function of the laser output power used for a given amplitude. The optimal amplitude tends to be larger for increased power.

The four-wire measurement was used to measure the resistance of the joints. Since the resistances of the base materials are assumed as equal for all samples, changes in contact resistance are due directly to changes in the contact area. A correlation between the strength of the connection contacts and the resistance can also be expected due to the increase in the tensile strength by an increased joining width. Figure 10 shows the measured resistance at a feed rate of $100 \mathrm{~mm} / \mathrm{s}$ plotted against the modulation amplitude.

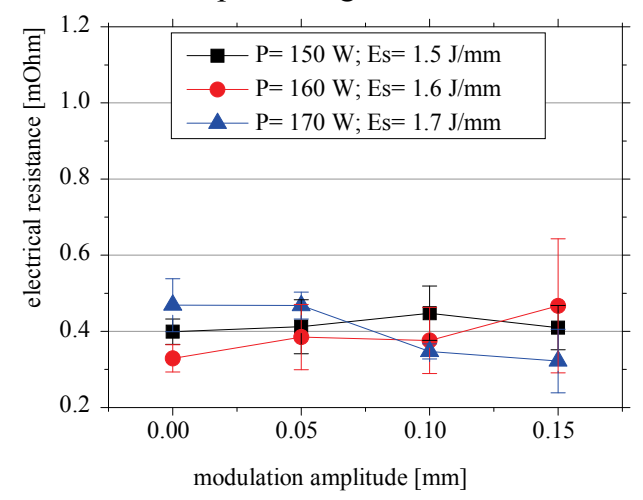

Fig. 10 Measured resistance of welds produced with $\mathrm{v}=100 \mathrm{~mm} / \mathrm{s}$

The course of the resistance at a laser output power of $170 \mathrm{~W}$ solely confirms the expectation that a larger connection area leads to a lower resistance. The samples with the greatest tensile forces show the smallest resistance. Contrary to this, the measured resistance for samples welded at $160 \mathrm{~W}$ laser output power increases with increasing amplitude, although larger tensile forces are achieved. Also, the assumption that a higher laser output power leads to a lower resistance cannot be supported. Almost all measurement 
points are within the standard deviation of the other power levels.

A similar situation arises for the measurements of samples welded at a feed rate of $110 \mathrm{~mm} / \mathrm{s}$. Again, the average measured values are within the standard deviation of the other power levels, so that no connection to the welding parameters can be derived. The measured resistance does not allow conclusions to be made about the connection area for these feed rates.

A correlation between the resistance and connection area is apparent for the welds at $\mathrm{P}=135 \mathrm{~W}$ and a feed rate of $90 \mathrm{~mm} / \mathrm{s}$ (Fig. 11).

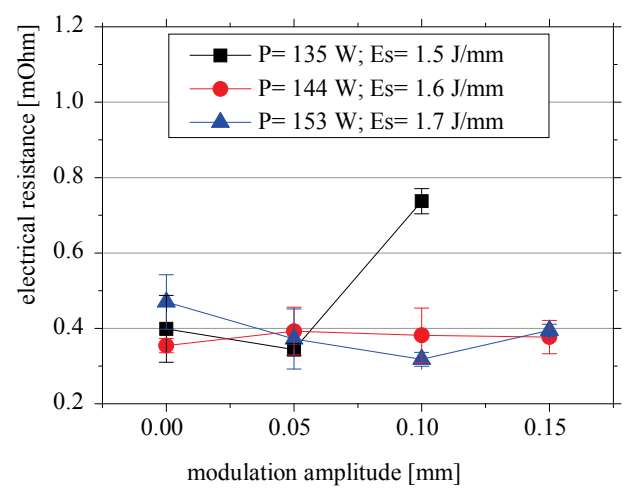

Fig. 11 Measured resistance of welds produced at $\mathrm{v}=90 \mathrm{~mm} / \mathrm{s}$

Basically, the course of the resistance behaves similarly to those in the feed rates of 100 and $110 \mathrm{~mm} / \mathrm{s}$. Only for samples welded at a laser output power of $135 \mathrm{~W}$ and an amplitude of $0.1 \mathrm{~mm}$ does the resistance equal $0.74 \mathrm{mOhm}$, which is significantly greater. These samples are the ones that were destroyed during the tensile tests conducted at a tensile force of about $100 \mathrm{~N}$ (Fig. 9). Here the connection is so weak that it has an impact on the resistance.

For the resistance of samples welded using other parameters, the fluctuations deviate from each other minimally. Therefore, identifying the welding parameters by resistance is not possible.

In consequence, the test method is either inappropriate or inaccurate, and therefore the resistance is largely independent of the welding parameters. However, it can be determined that exceptionally large resistances are based on a very weak connection.

In general, the mean resistance of the joints is in between $0.3 \mathrm{mOhm}$ and $0.6 \mathrm{mOhm}$ for all measurements except those made at $135 \mathrm{~W}$ and an amplitude greater than or equal to $0.1 \mathrm{~mm}$.

In the next step samples were thermally cycled and tensile tests and measurements of the resistance were conducted. The influence of thermal cycling was to be registered by comparing the results of the tensile tests without thermal cycling and those samples which were exposed in the climate chamber to the temperature changes. For the thermal cycling only the samples welded at a feed rate of $100 \mathrm{~mm} / \mathrm{s}$ were investigated.

In Figure 12, the maximum tensile forces of the samples with and without thermal cycling are compared for welds with a laser output power of $150 \mathrm{~W}$.

The measured maximum force for samples subjected to thermal cycling is lower than for samples without thermal cycling. A weakening might have occurred, but the results do not significantly differ. This also applies to samples welded at a laser output power of $160 \mathrm{~W}$ (Fig. 13).

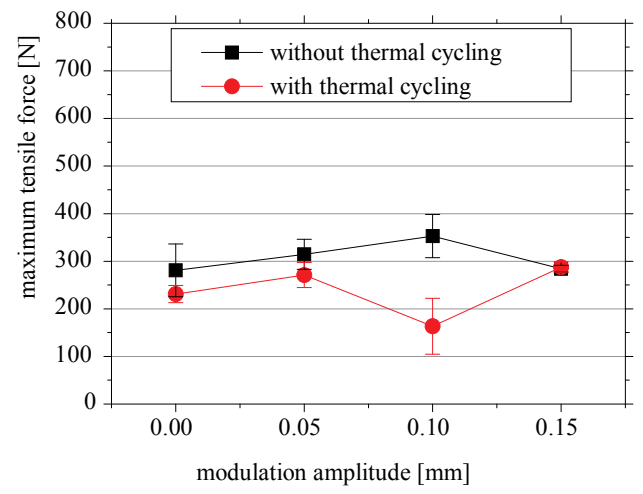

Fig. 12 Comparison of the measured maximum tensile force of welds produced at $150 \mathrm{~W}$ with and without thermal cycling

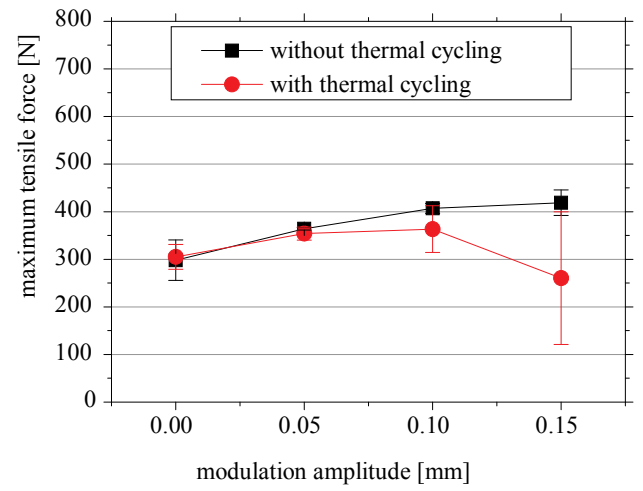

Fig. 13 Comparison of the measured maximum tensile force of welds produced at $160 \mathrm{~W}$ with and without thermal cycling

Especially for samples produced with the parameter $\mathrm{P}=160 \mathrm{~W}$ and $\mathrm{a} \leq 0.05 \mathrm{~mm}$, the measured tensile forces are very close together and, therefore, do not significantly differ from one another.

Samples welded at the upper power level of $\mathrm{P}=170 \mathrm{~W}$ do not show a significant weakening, either (Fig. 14). In particular, the samples welded without the use of the spatial modulation display no change in tensile force.

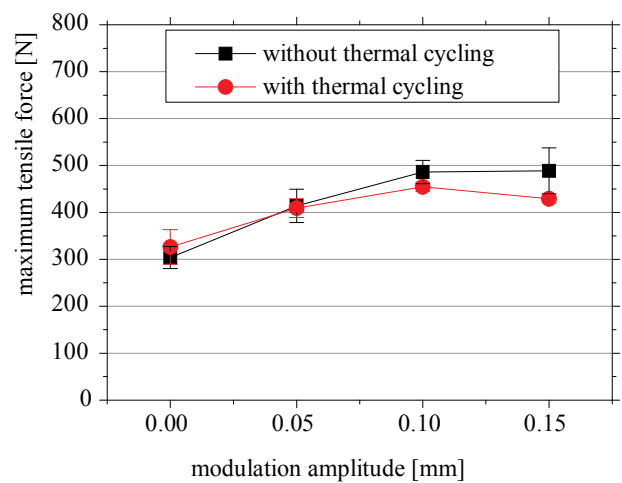

Fig. 14 Comparison of the measured maximum tensile force of welds produced at $170 \mathrm{~W}$ with and without thermal cycling

The largest deviation in the tensile force is observed in samples welded with the largest amplitude of $0.15 \mathrm{~mm}$. The highest influence of the thermal cycling occurs in the largest connection area for welds with laser output power of 
$160 \mathrm{~W}$ and $170 \mathrm{~W}$. But still, these values do not differ significantly.

This is confirmed by comparing the resistance measurements for welds with $150 \mathrm{~W}$ and $160 \mathrm{~W}$ (Fig. 15 and Fig. 16). Please note that these are only some of the same samples for the resistance measurements. For the measurements without influence of thermal cycling, five additional samples were used.

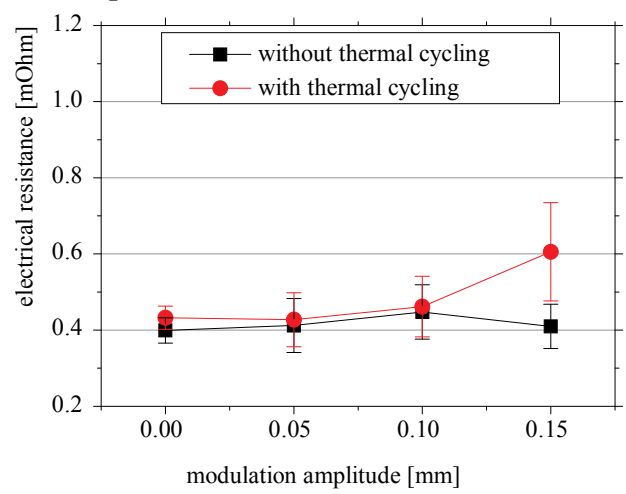

Fig. 15 Comparison of the measured resistances of welds produced at $150 \mathrm{~W}$ with and without thermal cycling

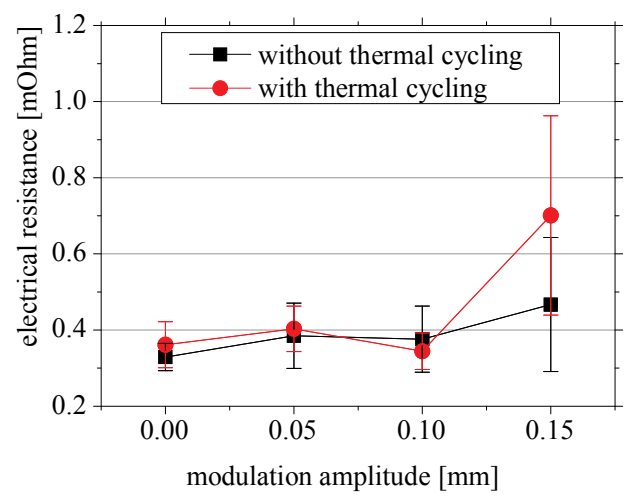

Fig. 16 Comparison of the measured resistances of welds produced at $160 \mathrm{~W}$ with and without thermal cycling

The measured resistances show each the same trend up to an amplitude of $0.1 \mathrm{~mm}$ within the margin of error. Only at the largest amplitude of $0.15 \mathrm{~mm}$ does an increase occur at about $0.25 \mathrm{mOhm}$.

For the highest energy input per unit length used (Fig. 17), this trend does not occur. Here, the measured resistances are so close together that no influence of the thermal cycling could be detected.

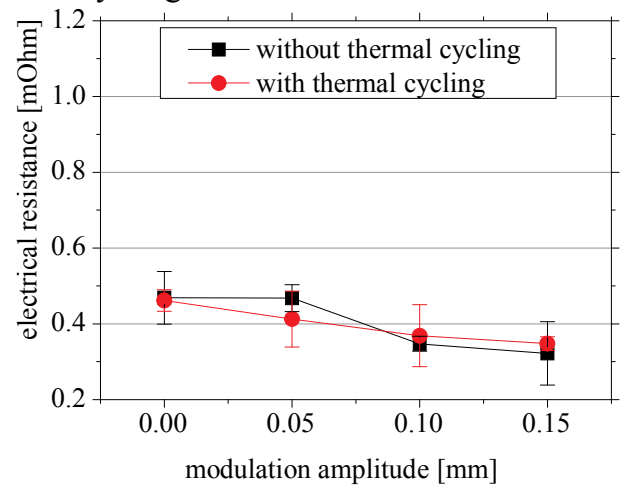

Fig. 17 Comparison of the measured resistances of welds produced at $170 \mathrm{~W}$ with and without thermal cycling

Overall, with larger amplitudes of the spatial modulation, an influence of the thermal cycling seems detectable despite a fairly low number of cycles of 60 , but the method must be enhanced so smaller changes are detectable with a smaller spread.

\section{Conclusion}

This paper examined laser micro welding of copper and steel for battery applications. The batteries are of the type 18650, and the cans are joined with $200 \mu \mathrm{m}$ thick CuSn6 sheet. Spatial modulation was used to examine the influence of welding parameters such as laser output power, feed rate and modulation amplitude for welding in a predefined process window. In particular, these tests identified/determined the effects on the tensile strength of the connection and on the electrical resistance of the joint. Furthermore, the susceptibility to thermal cycling of samples was evaluated.

To maximize the strength of the connection between the two materials, the process needs a favorable ratio of the amplitude of the spatial modulation with the other welding parameters. Overall, the copper sheet is reliably connected with the steel sheet of the battery by the laser beam microwelding. Especially when using spatial modulation, welds show a good stability towards an accidental full penetration of the can, since a wide connection area is produced without a deep penetration of the sheet materials.

In particular, the method of resistance measuring must be enhanced so smaller changes are detectable with a smaller spread.

The comparison to welding similar materials must be taken to quantify the effect of different thermal expansions of the copper-steel welds.

Further metallurgical studies are necessary to determine the precise composition and mixing of the two materials in the joint zone.

\section{Acknowledgments}

All the investigations were conducted in the context of the "Fraunhofer System Research for Electromobility II" project. The authors would also like to thank H\&T Marsberg for supplying the battery cans. The responsibility for this paper is taken by the authors.

\section{References}

[1] F. Schmitt, B. Mehlmann, J. Gedicke, A. Olowinsky, A. Gillner, R. Poprawe, Laser beam micro welding with high brilliant fiber lasers. Proc. of LAMP $2009-$ 5th Int. Congr. on Laser Advanced Materials Processing, June 29 - July 2, 2009, Kobe, Japan.

[2] R. Poprawe, F. Schmitt, J. Gedicke, B. Mehlmann, A. Olowinsky, A. Gillner, Systemtechnik zur örtlichen Leistungsmodulation beim Laserstrahl-Mikroschweißen. 4. Kolloquium Mikroproduktion. Editor.: F. Vollertsen, [et al] Bremen: BIAS Verl. 2009.

[3] A. Heider, P. Stritt, A. Hess, R. Weber, T. Graf, Process Stabilization at welding Copper by Laser Power Modulation, Physics Procedia, 12, 81-87, (2011)

[4] Deutsches Kupferinstitut: Data sheet CuSn6. 2005

[5] Haynes, W. M.: CRC Handbook of Chemistry and Physics. 92nd Edition. Taylor \& Francis, Oxford, 2011

[6] Sun, Z.; Ion, J.C.: Laser welding of dissimilar metal combinations. Journal of Materials Science, Volume 30, 17, 4205-4214, (1995)

(Received: July 23, 2013, Accepted: November 20, 2014) 